\title{
Uma abordagem prática do experimento de Oersted em sala de aula
}

\author{
Cacia Simone Arraes ${ }^{1}$, Leislhe Patrícia R. de Souza², Rogério Junqueira Prado 3 \\ 1,2,3 Universidade Federal de Mato Grosso (UFMG)
}

Palavras-chave: Aulas práticas, Ensino de Física, Experimento de Oersted, Eletromagnetismo.

\section{Introdução}

As escolas de ensino médio brasileiras enfrentam o grande desafio de despertar o interesse dos alunos na busca pelo conhecimento. Particularmente, ao se trabalhar com o ensino de Física, nota-se grande dificuldade e desinteresse por parte dos alunos. Segundo vários autores (SOUSA, 2010; MARTINS, 2014), um dos principais motivos seriam as aulas monótonas, cheias de cálculos, e sem conexões da teoria com a prática. Em função dessas dificuldades, tem-se buscado "aulas mais dinâmicas na tentativa de fazer do aluno um agente no processo de ensino-aprendizagem" (GUEDES, 2017), atribuindo ao docente a responsabilidade de disponibilizar conteúdos e/ou abordagens que despertem nos alunos o interesse pelo estudo/aprendizado e oriente-os rumo a uma nova maneira de construção do conhecimento.

Neste sentido, propõe-se neste trabalho a abordagem de um tema através da construção e análise de experimentos, uma vez que, de acordo com o relatado por outros autores (MARTINS, 2014; MORAES; JÚNIOR, 2014; QUINTAL; SANTOS; GASPAR, 2005; FILHO; CALUZI, 2009), a realização de experimentos durante as aulas permite uma maior interação entre professor e alunos, e destes últimos com os conceitos estudados, além de ser uma forma mais atraente de prender a atenção dos mesmos, contribuindo de maneira importante para o aprendizado.

Assim, decidiu-se pela construção de um experimento de baixo custo para se trabalhar conteúdos históricos e conceituais de eletromagnetismo. Foi escolhida a experiência de Oersted, que teve papel fundamental no desenvolvimento do eletromagnetismo. Indo além de uma simples demonstração, o experimento desenvolvido possibilita ao aluno verificar que o módulo do campo magnético produzido por um fio retilíneo infinito decresce com o inverso da distância.

\section{Metodologia e Material}

Este trabalho foi fundamentado segundo a teoria de aprendizagem de David Ausubel (AUSUBEL; NOVAK; HANESIAN, 1980). Para Moreira (2017, p.160), "Ausubel é um representante do cognitivismo e, como tal, propõe uma explicação teórica do processo de aprendizagem", focando sua teoria na aprendizagem significativa. De acordo com Ausubel apud Moreira e Masini (2001), a aprendizagem é significativa quando o material é potencialmente significativo e o aluno manifesta disposição para relacionar o novo conceito com os conceitos subsunçores. Assim, ao se propor o uso de experimentos durante as aulas, pretende-se que o docente potencialize estratégias para que os alunos possam organizar seus conhecimentos e fazer essa ponte, abrindo espaço para que ocorra aprendizado.

Para a realização desta pesquisa foram usadas metodologias ativas, aulas expositivas e a aplicação de um experimento. A pesquisa foi realizada em três etapas de 50 minutos e com alunos do terceiro ano do ensino médio. Na primeira etapa foi apresentado o conteúdo de magnetismo e eletricidade necessários para a compreensão do experimento. Na segunda etapa foi apresentada uma introdução histórica ao eletromagnetismo. Na última etapa foi realizada a aula experimental.

Para a construção do experimento foram utilizados: fio de cobre de $72 \mathrm{~cm}$; haste de $40 \mathrm{~cm}$; 02 pilhas alcalinas AAA; fita isolante; bússola; tábua de $32 \times 32 \mathrm{~cm}$; 36 tampinhas de caixa de leite; suporte para as pilhas; dois plugs (macho e fêmea); EVA; cola para EVA; 5 palitos de churrasco; régua de $30 \mathrm{~cm}$; multímetro.

\section{Resultados e Discussão}

Com a realização da primeira e segunda etapa observou-se o interesse dos estudantes em relação ao eletromagnetismo, e a associação dos conhecimentos prévios com os conceitos abordados. Em geral, os alunos se mostraram mais à vontade em debater conteúdos de eletricidade do que de magnetismo.

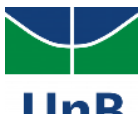


Após a confecção do experimento, os alunos verificaram a correlação entre o módulo da corrente elétrica no fio e a orientação da bússola para diferentes distâncias entre o fio e a bússola. O envolvimento e motivação dos alunos foi notório e todos se posicionaram para ver o deslocamento da agulha da bússola sob a influência do campo magnético produzido pela corrente no fio.

Logo após as primeiras observações, os alunos se dividiram em grupos para desenvolver as atividades propostas no roteiro. Eles interagiram bem entre si e para a resolução de exercícios que necessitavam de dados obtidos durante a experimentação. A elaboração de gráficos permitiu aos alunos verificar que o módulo do campo magnético gerado pelo fio varia com o inverso da distância.

\section{Conclusões}

O interesse dos estudantes em relação ao eletromagnetismo e sua associação com conhecimentos prévios sobre o tema facilitou o desenvolvimento das atividades. Foi possível concluir que as aulas de Física com a utilização de experimentos e atividades planejadas, mesmo que simples, enriquecem o elo entre teoria e prática, incentivando os alunos a serem construtores do seu conhecimento e proporcionando a construção dos conceitos estudados através da aplicação e análise dos fenômenos e leis físicas, colaborando para um ensino de qualidade com aprendizagem potencialmente significativa.

\section{Referências}

AUSUBEL, D. P., NOVAK, J. D., HANESIAN, H. Psicologia Educacional. Rio de Janeiro-RJ: Interamericana, 1980.

FILHO, M. P. S.; CALUZI, J. J. Sobre experiências relativas à imantação do ferro e do aço da corrente voltaica: uma tradução comentada do artigo escrito por François Arago. Revista Brasileira de Ensino de Física, n.1, v.31, 1603, 2009.

GUEDES, L. D. S. Experimentos com materiais alternativos: sugestão para dinamizar a aprendizagem de eletromagnetismo. 2017. 82 f. Dissertação de Mestrado, UFG, Catalão-GO, 2017.

MARTINS, M. Proposta para recriar o experimento de Oersted com materiais de baixo custo. 2014. 45 f. Monografia apresentada como pré-requisito para a conclusão do Curso de Licenciatura em Física, UEM. Maringá-PR, 2014.

MORAIS, J. U. P.; JUNIOR, R. S. S. Experimentos didáticos no ensino de Física com foco na aprendizagem significativa. Aprendizagem Significativa em Revista, n. 4, v. 3, 61-67, 2014.

MOREIRA, M. A. Teorias de aprendizagem. São Paulo-SP: EPU, 2017.

MOREIRA, M. A., MASINE, E. F. S. Aprendizagem significativa: a teoria de David Ausubel. São Paulo-SP: Centauro, 2001.

QUINTAL, J. R., SANTOS, W. M. S. \& GASPAR, M. B., Eletromagnetismo: experimentos para motivar o aprendizado. In: XVI Simpósio Nacional de Ensino de Física, 2005. Rio de Janeiro-RJ. SOUSA, A. J., A importância da Física Experimental no processo ensino aprendizado. 2010. 39.f. Monografia apresentada como pré-requisito para conclusão do Curso de Licenciatura em Física, UFU. Uberlândia-MG, 2010. 